Western University Scholarship@Western

1981

\title{
Value-Added Tax and the Theory of Tax Incidence
}

Kul B. Bhatia

Follow this and additional works at: https://ir.lib.uwo.ca/economicsresrpt

Part of the Economics Commons

Citation of this paper:

Bhatia, Kul B.. "Value-Added Tax and the Theory of Tax Incidence." Department of Economics Research Reports, 8117. London, ON:

Department of Economics, University of Western Ontario (1981). 


\section{RESEARCH REPORT 8117}

VALUE-ADDED TAX AND THE THEORY

OF TAX INCIDENCE

ECUROMES REFERERE GETRE

by

Ku1 B. Bhatia

$$
\text { MAR - } 61997
$$

WWIVERSITY OF WESTERN ONTARIO

\section{$\underline{\text { Abstract }}$}

A value-added tax is examined in a general-equilibrium model of tax-incidence incorporating primary factors and intermediate goods. Production coefficients are variable and demand is elastic. The principal result is that under assumptions of fixed coefficients and inelastic demand which have been commonly employed in the literature, VAT as well as the corporation income tax will be neutral. In the more general setting of this paper, only VAT, applied to every industry at equal rates will not affect relative factor- and commodity prices. Incidence and other economic effects of a partial VAT are also discussed. 


\section{VALUE-ADDED TAX AND THE THEORY \\ OF TAX INCIDENCE \\ by}

Kul B. Bhatia*

A good deal has been written about the value-added tax (VAT) in recent years. There are analytical studies dealing with incidence of VAT, its effects on commodity prices, and comparing VAT with various direct and indirect taxes it could replace. Considerable interest has been shown also in the role of VAT in tax harmonization, especially since the Neumark Report which advocated the adoption of a uniform VAT by all members of the European Economic Committee. Besides, there is a growing literature, mostly of a descriptive nature, about the actual experience of VAT in individual countries. ${ }^{1}$ Among the analytical writings, Oakland (1967) provides a theory of VAT, Friedlaender (1967) compares the price effects of VAT with those of indirect taxes such as a retail sales tax, a turnover tax, etc., and Aaron (1968), Vartholomeos (1974), and Dresch, Lin, and Stout (1977) consider questions involved in substituting VAT for the corporation income $\operatorname{tax}(C I T)$.

These studies provide valuable insights into the working of VAT and its relationship to other taxes, but they are quite restrictive in many ways because of the assumptions and approaches used by their authors. In Oakland's model, a consumer- and a capital good are produced, both using only primary factors, so there are no intermediate inputs. Although Friedlaender incorporates such inputs, she assumes fixed input-output coefficients and does not look at any factor taxes. Assuming fixed coefficients might not affect the results about sales- and commodity taxes she examines, but it does make 
a significant difference when taxes such as CIT are involved as the analysis in this paper will show. Input-output ratios are not allowed to vary by Aaron (1968), Vartholomeos (1974), and Dresch, Lin, and Stout (1977) as we11. These authors assume fixed demand vectors besides, and assign no specific role to primary factors. While such assumptions are convenient, they can be justified only in the short run or for "first-round analysis," as Dresch, Iin, and Stout call it. Moreover, these comparisons between VAT and CIT have not been made in a model of tax incidence. Therefore, a series of results about shifting of both taxes have to be extraneously imposed. ${ }^{2}$ What seems to be lacking in this literature is a general equilibrium framework which can provide a unified treatment of these and other issues about VAT.

The main purpose of this paper is to present a rigorous analysis of VAT in a general equilibrium model of tax incidence. Value added can be simply defined as total output minus intermediate inputs. The model, therefore, incorporates intermediate goods as well as primary factors. Elastic demand and flexible coefficients all round are also assumed. It is thus possible to analyze both demand and supply considerations in a general setting. Some of the results to be derived here are intuitively obvious and well known. For example, VAT applied to every industry at an equal rate will affect neither factor rewards nor output prices. The model nonetheless will also tackle other questions which are important but have not been rigorously answered in earlier work. Here are two examples: First, VAT does not always cover every activity. Shoup (1969) records that banks, insurance companies, and other financial institutions are exempt from the Danish value-added tax. McLure (1972) suggests that for administrative, political, and social-policy considerations, "from one-fifth to over half 
of personal consumption might be excluded from the tax base" [in the United States]. How are the incidence and other effects of VAT affected when all value-added cannot be taxed? Second, there is some evidence that elasticity of demand is not zero, and that cost-minimizing firms do try to substitute untaxed inputs for the taxed ones. How does VAT fare vis-à-vis CIT and other partial taxes if demand is elastic and it is possible to substitute primary factors for each other and for intermediate goods?

The theoretical framework is set out in section II. The model is modified to include inter-industry flows in Section III. Results about tax incidence are also reported in these sections, and section IV deals with the effects of various taxes on commodity prices. The only VAT considered here is of the "consumption type", which is equivalent to a VAT of the "income variety" or the "gross product type" in this model because there is no investment or depreciation.

\section{The Theoretical Framework}

There are two types of intermediate goods in any economy--those used entirely in the production process, and others which serve both as intermediate inputs and final goods. The former have been called "pure intermediate goods" while the latter have been treated as "inter-industry flows". The only difference between the two, for analytical purposes, is that there is no final demand for pure intermediate goods. It is nonetheless essential to consider them separately because they call for rather different theoretical specifications and lead to quite dissimilar results about incidence and other effects. 


\section{Pure Intermediate Good Case}

Let there be three goods, $x_{1}, x_{2}$, and $M . X_{1}$ and $x_{2}$ are final goods whereas $M$, being a purely intermediate commodity, is used up completely in their production. Labor and capital, the two primary factors in fixed supply, also appear in all production functions which display constant returns to scale. Full employment of factors and perfect competition in input and output markets are also assumed. It follows that firms minimize unit costs, and factor prices, net of any taxes, are equal across industries. Production coefficients in $M$ depend on $w$, the wage rate, and the rental of capital, $r$, whereas in $X_{1}$ and $x_{2}$ intermediate good's price $\left(P_{M}\right)$ will also affect these coefficients. A model of this type for CIT has been developed in Bhatia (1981), so only the key equations are presented here. Expressions (1) and (2) reflect zero-profit conditions that characterize competitive equilibria, full-employment of primary factors is ensured by (3) and (4), and the demand equation is given by (5)

$$
\begin{aligned}
& \theta_{\mathrm{L} 1} \mathrm{w}^{*}+\theta_{\mathrm{K} 1} \mathrm{r}^{*}=\mathrm{p}_{1}^{*} \\
& \theta_{\mathrm{L} 2} \mathrm{w}^{*}+\theta_{\mathrm{K} 2} \mathrm{r}^{*}=\mathrm{p}_{2}^{*} \\
& \lambda_{\mathrm{L} 1} \mathrm{X} \stackrel{*}{*}+\lambda_{\mathrm{L} 2} \mathrm{X}_{2}^{*}=\mathrm{L}^{*}-\left(\lambda_{\mathrm{L} 1} \mathrm{R}_{\mathrm{L} 1}^{*}+\lambda_{\mathrm{L} 2} \mathrm{R}_{\mathrm{L} 2}^{*}\right) \\
& \lambda_{\mathrm{K} 1} \mathrm{X}_{1}^{*}+\lambda_{\mathrm{K} 2} \mathrm{X}_{2}^{*}=\mathrm{K}^{*}-\left(\lambda_{\mathrm{K} 1} \mathrm{R}_{\mathrm{K} 1}^{*}+\lambda_{\mathrm{K} 2} \mathrm{R}_{\mathrm{K} 2}^{*}\right) \\
& \mathrm{X}_{1}^{*}=\epsilon\left(\mathrm{p}_{1}^{*}-\mathrm{p}_{2}^{*}\right)
\end{aligned}
$$

where asterisks denote proportional changes, $\lambda_{i j}$ is the proportion of $i^{\text {th }}$ primary factor used directly or indirectly (via the intermediate good) in the production of $j^{\text {th }}$ final good, $R^{\prime}$ s represent gross input-output ratios and $\theta^{\prime} s$

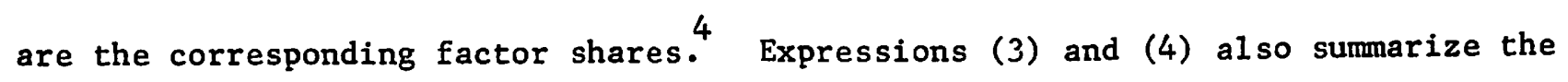
structure of production in this model, and $\epsilon$ is the income compensated elasticity of demand. 5 
A VAT in this framework is a tax at equal rates on labor and capital used directly in each industry. If the tax is levied in $x_{1}$ at rate $t{ }^{\text {' }}$ expression (1) will be replaced by (6):

$$
\theta_{\mathrm{L} 1} \mathrm{w}^{*}+\theta_{\mathrm{K} 1} \mathrm{r}^{*}+\left(\rho_{\mathrm{L} 1}+\rho_{\mathrm{K} 1}\right) \mathrm{T}_{\mathrm{V} 1}^{*}=\mathrm{P}_{1}^{*}
$$

where $\rho_{\mathrm{L} 1}$ and $\rho_{\mathrm{K} 1}$, respectively, are the share of labor and capital used directly in $x_{1}\left(e_{\cdot g}, \rho_{L 1}={ }^{w} a_{L 1} / p_{1}\right.$, etc. $)$, and $T_{V 1}^{*}=\left(1+t_{V 1}\right) *{ }_{\bullet}^{6}$ By contrast, a tax on capital in $X_{1}$ at rate $t_{K 1}$ will lead to (7)

$$
\theta_{\mathrm{L} 1} \mathrm{w}^{*}+\theta_{\mathrm{K} 1} \mathrm{r}^{*}+\rho_{\mathrm{K} 1} \mathrm{~T}_{\mathrm{K} 1}^{*}=\mathrm{P}_{1}^{*}
$$

where $\mathrm{T}_{\mathrm{K} I}^{*}=\left(1+\mathrm{t}_{\mathrm{K} 1}\right)^{*}$.

The above framework, to all intents and purposes, is an extension of the Harberger model to incorporate intermediate goods. As in that model, the key to tax incidence is the behavior of factor shares. If the wage-rental ratio remains unchanged in the face of a tax, relative shares of labor and capital in national income do not alter because of the assumptions of full employment and fixed factor endowments. Consequently, the ultimate burden of the tax in question falls on labor and capital in proportion to their initial contribution to national income. However, a factor whose relative price declines will have to suffer more. The crucial step, therefore, is to obtain a solution for $w / r$, the wage-rental ratio in the presence of various taxes, and that is done by equating the proportionate change in supply of $\mathrm{x}_{1}$ to the corresponding change in its demand. To simplify this operation, all initial prices are set to unity by a suitable choice of units, $L^{*}=K^{*}=0$ because of fixed supply of factors, and $w$ is chosen as the numeraire in terms of which all other prices are reckoned. This leads to the additional advantage that $w^{*}$ also becomes zero, so proportional changes in the wagerental ratio are indicated by $r *$ alone. The solution for $r^{*}$ is derived by 
first solving (3) and (4) for $X_{1}^{*}$ (supply) and equating it to $X_{1}^{*}$ (demand) in (5) after substituting for $p_{1}^{*}$ and $p_{2}^{*}$ from (1) and (2). This procedure yields expression (8) for VAT in $\mathrm{X}_{1}$ and (9) for a tax on capital in that industry.

$$
\begin{aligned}
& r *=\frac{A \in\left(\rho_{K 1}+\rho_{L 1}\right)-B\left(\rho_{L M} \rho_{K 1} \rho_{M 1} \sigma_{K M}^{1}-\rho_{L 1} \rho_{K M} \rho_{M 1} \sigma_{L M}^{1}\right) / \theta_{L 1} \theta_{K 1}}{\epsilon\left(\theta_{K 2}-\theta_{K 1}\right) A+B G+F} T * 1 \\
& \mathrm{r}^{*}=\frac{\mathrm{A} \epsilon \rho_{\mathrm{K} 1}-\mathrm{B}\left(\rho_{\mathrm{Kl}} \rho_{\mathrm{Ml}} \rho_{\mathrm{LM}} \sigma_{\mathrm{KM}}^{1}+\rho_{\mathrm{Ll}} \rho_{\mathrm{K} 1} \sigma_{\mathrm{LK}}^{1}\right) / \theta_{\mathrm{Ll}} \theta_{\mathrm{K} 1}}{\epsilon\left(\theta_{\mathrm{K} 2}-\theta_{\mathrm{K} 1}\right) \mathrm{A}+\mathrm{BG}+\mathrm{F}} \mathrm{T}_{\mathrm{K} 1}
\end{aligned}
$$

Here $A$ is $K_{1} / K_{2}-L_{1} / L_{2}, B=\theta_{X 1} \frac{L_{1}}{L_{2}}+\theta_{L 1} \frac{K_{1}}{K_{2}}, F=\left(\beta_{1}+\delta\right) / \theta_{K 2} \theta_{L 2}$, and $G=$ $\left(\alpha_{1}+\xi\right) / \theta_{\mathrm{K} 1} \theta_{\mathrm{L} 1}$. Also, $\alpha_{1}=\rho_{\mathrm{L} 1} \rho_{\mathrm{K} 1} \sigma_{\mathrm{LK}}^{1}+\rho_{\mathrm{KM}}^{2} \rho_{\mathrm{L} 1} \rho_{\mathrm{Ml}} \sigma_{\mathrm{LM}}^{1}+\rho_{\mathrm{LM}}^{2} \rho_{\mathrm{K} 1} \rho_{\mathrm{M} 1} \sigma_{\mathrm{KM}}^{1}$, and $\beta_{1}=\rho_{L 2} \rho_{K 2} \sigma_{L K}^{2}+\rho_{K M}^{2} \rho_{L 2} \rho_{M 2} \sigma_{L M}^{2}+\rho_{L M}^{2} \rho_{K 2} \rho_{M 2} \sigma_{K M}^{2}$. Both $\alpha_{1}$ and $\beta_{1}$ are sums of various elasticities of substitution $\left(\sigma^{\prime} s\right)$ premultiplied by factor shares in $X_{1}$ and $X_{2}$. Similar expressions for the intermediate good are $\xi=\rho_{L M} \rho_{K M} \rho_{M 1} \sigma_{L K}^{M}$ and $\delta=\rho_{\mathrm{LM}} \rho_{\mathrm{KM}} \rho_{\mathrm{M} 2} \sigma_{\mathrm{LK}}^{\mathrm{M}}{ }^{8}$

Since gross input-output ratios, $R^{\prime} s$, ultimately depend on relative input prices, $R^{*}$ 's can be expressed in terms of $\sigma^{\prime} s, w^{*}$, and $r^{*}$ as shown in the Appendix. For example, with $w^{*}=0, R_{L 2}^{*}=\left(B_{1}+\delta\right) r^{*} / \theta_{L 2}$, and in case of a VAT in $x_{1}, R_{L 1}^{*}=\left(\alpha_{1}+\xi\right) r^{*} / \theta_{L 1}+\rho_{M 1}\left(\rho_{L M} \rho_{K 1} \sigma_{K M}^{1}-\rho_{L 1} \rho_{K M} \sigma_{L M}^{1}\right) T_{V 1}^{*} \cdot$ All such expressions for $R^{*}$ 's have also been used in arriving at (8) and (9). It is easy to verify that in the absence of an intermediate good (9) will reduce to the solution derived by Harberger (1962). The intermediate good mainly contributes a number of additional elasticities of substitution to both (8) and (9). Only $\sigma_{L K}^{1}$ appears in Harberger's equations. There is of course the distinction between gross and net capital-labor ratios as well. An industry which is relatively capital intensive in net terms $\left(a_{i j}{ }^{\prime} s\right)$ might turn out to be labor intensive when primary factors used via $M$ are taken into account. 
Other Taxes

When other taxes are levied, solutions for $r *$ can be similarly derived. R*, of course, will vary slightly from one tax to the next. For instance, if a tax on labor is imposed in $x_{1}, R_{L 1}^{*}=\left[\left(\alpha_{1}+\xi\right) r *\right.$

- $\left.\left(\rho_{I 1} \rho_{K 1} \sigma_{I K}^{1}+\rho_{L 1} \rho_{M 1} \rho_{K M} \sigma_{I M}^{1}\right)\right] / \theta_{L 1}$. Without going into details, the following solutions are presented. The denominator in all cases is the same as in (8) and is denoted by $D_{1}$.

An excise tax on $x_{1}\left(t_{1}\right)$ :

$$
\mathrm{r} *=\frac{\varepsilon A}{D_{1}} T_{1}^{*}
$$

A value-added $\operatorname{tax}$ in $x_{2}\left(t_{v 2}\right)$

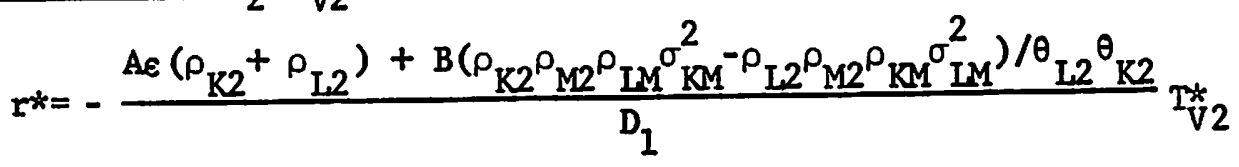

A tax on capital in $X_{2}\left(t_{K 2}\right)$

$$
r^{*}=-\frac{A \in \rho_{\mathrm{K} 2}+\left(\rho_{\mathrm{L} 2} \rho_{\mathrm{K} 2} \sigma_{\mathrm{LK}}^{2}+\rho_{\mathrm{K} 2} \rho_{\mathrm{M} 2} \rho_{\mathrm{LM}} \sigma_{\mathrm{KM}}^{2}\right) / \theta_{\mathrm{K} 2} \theta_{\mathrm{L} 2}}{\mathrm{D}_{1}} \mathrm{~T}_{\mathrm{K} 2}^{*}
$$

An excise tax on $x_{2}\left(t_{2}\right)$

$$
\mathrm{r}^{*}=-\frac{\epsilon \mathrm{A}}{\mathrm{D}_{1}} \mathrm{~T}_{2}^{*}
$$

An excise tax on the intermediate good $M\left(t_{M}\right)$ :

$$
r^{*}=\frac{A \epsilon\left(\rho_{M 1}-\rho_{M 2}\right)+\rho_{M 1} B\left(\rho_{L M} \rho_{K 1} \sigma_{K M}^{1}-\rho_{K M} \rho_{L 1} \sigma_{L M}^{1}\right) / \theta_{L 1} \theta_{K 1}+\rho_{M 2}\left(\rho_{K 2} \rho_{L M} \sigma_{K M}^{2}-\rho_{L 2} \rho_{K M} \sigma_{L M}^{2}\right) / \theta_{L 2} \theta_{K 2}}{D_{1}} T_{M}^{*}
$$

A VAT in $M$ also leads to the same solution for $r *$ as in (14). This should be intuitively obvious because value added in $M$ is simply equal to value of total output, for no intermediate inputs are involved. An excise tax, therefore, 
is equal to VAT which in turn amounts to an equal rate tax on labor and capital. These equalities among various taxes do not hold in case of the other two goods because of the part played by the intermediate good. Equation (8), for instance, will not reduce to (10) even when fixed factor coefficients are assumed $\left(\sigma^{\prime} s=0\right)$ because $\rho_{\mathrm{Kl}}+\rho_{\mathrm{Il}}<1$.

\section{The Neutrality of VAT}

A strong argument in favor of VAT is that it leaves relative factor prices unchanged. The above results show that neutrality is certainly not unique to VAT. If factor proportions are the same in the two industries $(A=0)$ or demand is inelastic $(\epsilon=0)$, an excise $\operatorname{tax}$ in $X_{1}$ or $x_{2}$ will also not affect the wage-rental ratio. Moreover, if $\mathrm{A}$ or $\epsilon$ equals zero, and capital cannot be substituted for labor or the intermediate good in the taxed industry, even a tax on capital in $X_{1}$ will be neutral. In equation (9), which deals with CIT, if $\mathrm{A}=\epsilon=\sigma_{\mathrm{KM}}^{1}=\sigma_{\mathrm{LK}}^{1}=0, \mathrm{H}^{*}=0$. Similarly, a tax on capital in $\mathrm{X}_{2}$ will also not affect $w / r$ if $A$ or $\varepsilon, \sigma_{L K}^{2}$ and $\sigma_{K M}^{2}$ are zero.

It is important to recognize in this context that, taking one industry at a time, VAT has no better claims to neutrality than any other tax: $r *$ can have any sign and magnitude in (8), (9), and (10), or in (11), (12), and (13). Consider, for instance, VAT and CIT, a comparison between (8) and (9), assuming that $X_{1}$ is the corporate sector. For $r *$ to be zero in either case, $A$ or $\epsilon$, and $\sigma_{K M}^{1}$ must be zero. In addition, VAT will require that $L$ and $M$ be used in a fixed ratio in $X_{1}$, whereas CIT will need fixed proportions between $\mathrm{K}$ and $\mathrm{L}$. Roughly the same restrictions are thus needed to keep wagerental ratio constant under CIT and VAT. VAT, however, beats these other taxes hands down when the economy as a whole is considered. A uniform factor tax or a commodity tax in every industry will generally cause a change in relative factor prices. For example, equations (10), (13), and (14) do not 
add up to zero when the excise-tax rate is the same everywhere. As long as VAT is levied at an equal rate, with no industry exempted or treated differently, the wage-rental ratio will not alter: the sum of equations (8), (11), and (14) will always be zero when the tax rates are the same. Here it is worth noting that a uniform excise $\operatorname{tax}$ in $X_{1}$ and $X_{2}$ will not be distortionary although VAT similarly confined to the final-good industries will alter the wage-rental ratio unless value-added is the same proportion of total output in each industry,

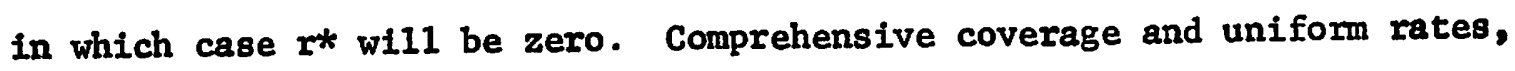
therefore, are preconditions for VAT's neutrality in the absence of any restrictions on $\sigma^{\prime} s, \epsilon$, or $A$. These preconditions nonetheless are rarely met in the real world. For example, Cnossen (1981) reports that in the Netherlands, services such as health, housing, and welfare are exempt, about 50 categories of goods are taxed at 4 per cent and the rest at 18 per cent. Almost every country which levies a VAT at present has similar exemptions and rate structures. Neutrality of VAT, obviously, is not its most coveted characteristic. Note, finally, that if demand is inelastic and factor proportions fixed, as has been assumed in many studies cited earlier, VAT, levied in one industry or the entire economy, at uniform or different rates, will invariably leave the wage-rental ratio intact. In (8), (11), and (14), r* $=0$ whenever $\epsilon=\sigma_{\mathrm{KM}}^{1}=\sigma_{I M}^{1}=\sigma_{\mathrm{KM}}^{2}=\sigma_{\mathrm{IM}}^{2}=0$. of course, under these restrictions, a partial or general excise tax will also be neutral.

\section{Incidence of VAT}

As indicated above, tax-incidence in this model is determined by $r *$. Notice first that $D_{1}$ is always positive: $B, G$, and $F$ are positive by definition, $A$ and $\left(\theta_{K 2}-\theta_{K 1}\right)$ have opposite signs and $\epsilon$ is negative. The sign of $r *$, therefore, depends on the numerators of various expressions. The following propositions can be derived: 
1. If VAT is levied in only one industry, and the intermediate good must be used in fixed proportions with labor, tax-burden will fall more heavily on capital if the taxed industry is relatively capital intensive: $r *$ will be negative, in (8) if $\sigma_{L M}^{1}=0$ and $A>0$, and in $(11)$, if $\sigma_{L M}^{2}=0$ and $\mathrm{A}<0$ (which implies that $\mathrm{X}_{2}$ is more capital intensive). It is obvious that this result will hold even if the intermediate good cannot be substituted for capitalas well $\left(\sigma_{\mathrm{KM}}^{1}=\sigma_{I M}^{1}=\sigma_{\mathrm{KM}}^{2}=\sigma_{I M}^{2}=0\right)$.

2. Elasticity of substitution between the two primary factors affects the magnitude but not the sign of $r *$ A VAT here is an equal rate tax on labor and capital, there is thus no tax-induced distortion between them in the taxed industry. Both $\sigma_{\mathrm{KL}}^{1}$ and $\sigma_{\mathrm{KL}}^{2}$ appear only in $\mathrm{D}_{1}$, as components of $\alpha_{1}$ and $\beta_{1}$. As either of these $\sigma^{\prime}$ 's becomes larger, $r *$ gets smaller. In the limit, $\mathrm{r} * \rightarrow 0$ as $\sigma_{\mathrm{KL}}^{1}$ or $\sigma_{\mathrm{KL}}^{2} \rightarrow \infty$.

3. If the intermediate good must be used in a fixed ratio with both primary factors in the taxed industry, the incidence of VAT will depend only on gross factor intensities: if $\sigma_{\mathrm{KM}}^{1}=\sigma_{\mathrm{LM}}^{1}=0$ in (8), $\mathrm{r} * \gtreqless 0$ as $\mathrm{A} \lesseqgtr 0$. If VAT is confined to $\mathrm{x}_{2}$, and $\sigma_{\mathrm{KM}}^{2}=\sigma_{\mathrm{LM}}^{2}=0, \mathrm{r} * \gtreqless<$ as $\mathrm{A} \stackrel{\gtrless}{\gtrless}$.

4. If all factor proportions are fixed throughout the economy, elasticity of demand has no bearing on the incidence question. If all $\sigma$ 's are zero, in (8), $r *=\left(\rho_{K 1}+\rho_{L 1}\right) /\left(\theta_{K 2}-\theta_{K 1}\right)$, and in (11) $r *=-\left(\rho_{K 2}+\rho_{L 2}\right) /\left(\theta_{K 2}-\theta_{K 1}\right)$. clearly, the sign of $\mathrm{r} *$ depends only on $\left(\theta_{\mathrm{K} 2}-\theta_{\mathrm{K} 1}\right)$.

It does not follow, however, that when factor proportions are fixed everywhere, the intermediate good should be left out. A model with only final goods would be much less complicated than the one used here, but it could lead to incorrect results about both the sign and magnitude of $r *$. The reason lies in $\mathrm{A}$ which denotes gross factor intensities here. If only 
final goods are assumed, net capital-labor ratios will be considered, and ranking of factor intensities in net and gross terms can be the opposite of each other. It is possible that $\mathrm{K}_{1} / \mathrm{K}_{2}$ might be greater than $\mathrm{L}_{1} / \mathrm{L}_{2}(A>0)$, while the net ratio, $K_{1}^{\prime} / K_{2}^{\prime}$ is less than $L_{1}^{\prime} / L_{2}^{\prime}$. In terms of factor shares, it can happen that $\theta_{\mathrm{K} 1}$ is greater than $\theta_{\mathrm{K} 2}$ whereas $\rho_{\mathrm{K} 1}<\rho_{\mathrm{K} 2}$ (recall that $\rho^{\prime} s$ will be computed from factors directly employed in each industry). In this situation, when input-output coefficients are fixed, $r^{*}$ will be positive in (8) when $\theta^{\prime}$ 's are considered, but negative when only $\rho^{\prime} s$ are taken into account. This complication does not arise in a model with inter-industry flows where A will have the same sign under either specification. 9

Other results of this sort can also be deduced from (8) and (11). The key point, worth reiterating, is that so long as VAT is not applied to every industry, it is not much different from any other partial tax levied on production or on the use of a particular factor, especially when fixed production coefficients are assumed. As a practical matter, it is not always possible to extend VAT to every activity. Germany and Denmark exempt financial services, and it is sometimes argued that food and other necessaries which take the 1ion's share in low-income budgets, should also not be taxed or taxed at lower rates. 10 When such provisions are made, VAT obviously ceases to be a neutral tax. Moreover, it is not clear that in such cases VAT is still the best tax to levy. Consider a hypothetical case in which only final goods can be taxed. Then an excise tax will work much better than a VAT. In the present model, a uniform excise tax on $\mathrm{x}_{1}$ and $\mathrm{x}_{2}$ will be neutral while VAT will alter the wage-rental ratio. In fact, in this situation, the excise tax, and not VAT, will end up taxing all value-added in the economy. 
III. Inter-Industry Flows

To deal with intermediate inputs which also serve as final goods,

it is assumed now that the economy produces only two goods, $\mathrm{x}_{1}$ and $\mathrm{x}_{2}$.

Total output used for meeting final demand is $x_{i}$, and $x_{i j}(i, j=1,2 ; i \neq j)$

becomes an intermediate input. Each commodity is produced with the help

of capital, labor, and the other good. As before, constant returns to scale,

full employment, competitive markets, and complete flexibility of all

prices and production coefficients are assumed. The demand equation (5) is

also retained, except that $x_{1}$ replaces $x_{1}$.

Full-Emp loyment Conditions

$$
\begin{aligned}
& a_{L 1}\left(x_{1}+x_{12}\right)+a_{L 2}\left(x_{2}+x_{21}\right)=L \\
& a_{K 1}\left(x_{1}+x_{12}\right)+a_{K 2}\left(x_{2}+x_{21}\right)=K
\end{aligned}
$$

Or, equivalently,

$$
\begin{aligned}
& R_{L 1} x_{1}+R_{L 2} x_{2}=L \\
& R_{K 1} x_{1}+R_{K 2} x_{2}=K
\end{aligned}
$$

where $R_{i j}$ is the amount of the $\underline{i}^{\text {th }}$ primary factor used directly or indirectly in producing one unit of the $i^{\text {th }}$ final good. For example, $R_{K 1}=\left(a_{K 1}+a_{K 2} \cdot a_{21}\right) /$ $\left(1-a_{12} \cdot a_{21}\right)$. It is further assumed that $a_{12} \cdot a_{21}<1$, which makes all $R_{i j}$ 's positive and ensures positive outputs for the two final goods.

In equilibrium, output prices equal minimum unit costs, so we can write

$$
\begin{aligned}
& a_{L 1} w+a_{K 1} r+a_{21} p_{2}=p_{1} \\
& a_{L 2} w+a_{K 2} r+a_{12} p_{1}=p_{2},
\end{aligned}
$$

and input-output coefficients are determined by

$$
a_{1 j}=a_{i j}\left(w, r, p_{k}\right) \quad(i=L, K, 1,2 ; j, k=1,2 ; j \neq k)
$$


Resource allocation in this framework is determined by input and output prices which can be altered by factor and commodity taxes. Differentiation of equations (17) and (18) yields the following structural relations:

$$
\begin{aligned}
& \lambda_{L 1} x_{1}^{*}+\lambda_{L 2} x_{2}^{*}=L *-\left(\lambda_{L 1} R_{L 1}^{*}+\lambda_{L 2} \dot{R}_{L 2}^{*}\right) \\
& \lambda_{\mathrm{K} 1} \mathrm{x}_{1}^{*}+\lambda_{\mathrm{K} 2} \mathrm{x}_{2}^{*}=\mathrm{K}^{*}-\left(\lambda_{\mathrm{K} 1} \mathrm{R}_{\mathrm{K} 1}^{*}+\lambda_{\mathrm{K} 2} \mathrm{R}_{\mathrm{K} 2}^{*}\right)
\end{aligned}
$$

where $\lambda_{i j}$ is the proportion of tatal endowment of the $\underline{i}^{\text {th }}$ primary factor used directly and indirectly in industry $\dot{i}\left(e_{. g} \cdot, \lambda_{K 1}=R_{K 1} x_{1} / K\right.$, etc.).

Similarly, from (19) and (20), assuming that firms minimize unit costs, we get:

$$
\begin{aligned}
& \rho_{\mathrm{Ll}} \mathrm{w}^{*}+\rho_{\mathrm{Kl}} \mathrm{r}^{*}+\rho_{21} \rho_{2}^{*}=\mathrm{P}_{1}^{*} \\
& \rho_{L 2}{ }^{* *+}+\rho_{K 2} r^{*+}+\rho_{12} p_{1}^{*}=p_{2}^{*}
\end{aligned}
$$

which leads to:

$$
\begin{aligned}
& \theta_{\mathrm{Ll}} \mathrm{w}^{*}+\theta_{\mathrm{KI}} \mathrm{r}^{*}=\mathrm{P}_{1}^{*} \\
& \theta_{\mathrm{L} 2}{ }^{\mathrm{w}^{*}+\theta_{\mathrm{K} 2}} \mathrm{r}^{*}=\mathrm{P}_{2}^{*}
\end{aligned}
$$

Here $\theta_{1 j}$ denotes the total distributive share of the $\underline{i}^{\text {th }}$ primary factor in industry 1 (for instance, $\theta_{K 2}=R_{K 2} r \mid n_{2}$ ), and $\rho_{1 j}$ represents direct factor shares (e.g., $\rho_{\mathrm{K} 2}=a_{\mathrm{K} 2} r\left(p_{2}\right)$. For each industry, $\rho$ 's as well as $\theta^{\prime} s$ will add up to unity (e.g., $\rho_{\mathrm{L} 1}+\rho_{\mathrm{K} 1}+\rho_{21}=1, \theta_{\mathrm{L} 2}+\theta_{\mathrm{K} 2}=1$, and so on).

The Role of Various Taxes

As in the earlier model, value-added is the difference between value of output and intermediate inputs used in the production process. Accordingly, VAT is a tax on labor and capital directly used in each industry. A VAT in $\mathrm{X}_{1}$ will necessitate a revision of equation (19) which becomes (28):

$$
a_{L 1} w\left(1+t_{V 1}\right)+a_{K 1} r\left(1+t_{V 1}\right)+a_{21} p_{2}=p_{1}
$$


Equations (26) and (27) will be replaced by (29) and (30) (setting $w^{*}=0$ ):

$$
\begin{aligned}
& \theta_{\mathrm{K} 1} \mathrm{r}^{*}+\gamma\left(\rho_{\mathrm{L} 1}+\rho_{\mathrm{K} 1}\right) \mathrm{T}_{\mathrm{V} 1}^{*}=\mathrm{p}_{1}^{*} \\
& \theta_{K 2}{ }^{I^{*}}+\gamma \rho_{12}\left(\rho_{L 1}+\rho_{K 1}\right) T_{V 1}^{*}=p_{2}^{*}
\end{aligned}
$$

where $\gamma=1 /\left(1-\rho_{12} \rho_{21}\right)$, $\rho^{\prime} s$ and $\theta^{\prime}$ 's denote factor shares gross of tax, and $T_{V 1}^{*}=\left(1+t_{V 1}\right)^{*}$. Although $\rho^{\prime} s$ and $\theta^{\prime} s$ represent the same concepts as in the earlier model, their magnitudes will not be the same in the two cases because $R$ 's are defined here to reflect inter-industry flows. For instance, $\mathrm{R}_{\mathrm{K} 1}=\left(\mathrm{a}_{\mathrm{K} 1}+\mathrm{a}_{\mathrm{K} 2} \cdot \mathrm{a}_{21}\right) /\left(1-\mathrm{a}_{12} \cdot \mathrm{a}_{21}\right)$, but if $\mathrm{X}_{2}$ is only a pure intermediate good, $R_{K 1}$ will be equal to $a_{K 1}+a_{K 2} \cdot a_{21}$. It follows that $R_{i j}^{*}$ 's will also be quite different from those in the earlier model. For example, if a tax on capital in $x_{1}\left(t_{K 1}\right)$ is the only tax in the economy, the following expressions can be derived.

$$
\begin{aligned}
& R_{L 1}^{*}=\frac{\left(\alpha_{2}+\rho_{21} \beta_{2}\right) r^{*}}{\Omega_{L}}+\frac{T_{K 1}^{*}}{\Omega_{L}}\left[\rho_{L 1} \rho_{K 1} \sigma_{L K}^{1}+\rho_{21} \rho_{K 1} \theta_{L 2} \sigma_{K 2}^{1}\left(1-\gamma \rho_{12} \rho_{21}\right)+\gamma_{L 1} \rho_{21} \rho_{12}{ }^{\rho} K 1 \theta_{K 2} \sigma_{L 2}^{1}\right.
\end{aligned}
$$

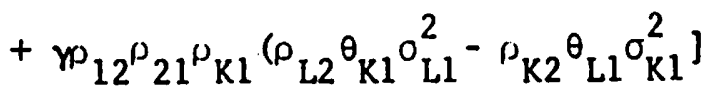

$$
\begin{aligned}
& R_{K 1}^{*}=-\frac{\alpha_{2}+\rho_{21} \beta_{2}}{\Omega_{K}}-\frac{T_{1 K}^{*}}{\Omega_{K}}\left[\rho_{K 1} \rho_{L 1} \sigma_{L K}^{1}+\rho_{K 1} \rho_{21} \theta_{L 2} \sigma_{K 2}^{1}(1-\gamma)_{K 1} \rho_{21}\right)+\gamma \rho_{K 1} \rho_{L 1} \rho_{21} \rho_{12} \theta_{K 2} \sigma_{L 2}^{1} \\
& +\gamma \rho_{12} \rho_{21} \rho_{K 1}\left(\rho_{L 2} \theta_{K 1} \sigma_{L 1}^{2}-\rho_{K 2}{ }^{\theta}{ }_{L 1} \sigma_{K 1}^{2}\right] \\
& \mathrm{R}_{\mathrm{L} 2}^{*}=\frac{\left(\beta_{2}+\rho_{12} \alpha_{2}\right) r^{*}}{\eta_{\mathrm{L}}}+\frac{\mathrm{T}_{1 \mathrm{~K}}^{*}}{\eta_{\mathrm{L}}}\left[\rho_{12} \rho_{\mathrm{Kl}} \rho_{\mathrm{L} 1} \sigma_{\mathrm{LK}}^{1}+\rho_{21} \rho_{12} \rho_{\mathrm{K} 1}{ }^{\theta_{L 2}} \sigma_{\mathrm{K} 2}^{1}\left(1-\gamma \rho_{12}{ }^{\rho_{\mathrm{K} 1}}\right)\right. \\
& \left.+\gamma \rho_{12} \rho_{K 1}\left(\rho_{L 2} \theta_{K 1} \sigma_{L 1}^{2}-\rho_{K 2} \theta_{L 1} \sigma_{K 1}^{2}\right)+\gamma \rho_{12}^{2} \rho_{L 1} \rho_{K 1} \rho_{21} \theta_{K 2}{ }^{1}{ }_{L 2}\right] \\
& R_{K 2}^{*}=-\frac{\left(\beta_{2}+\rho_{12} \alpha_{2}\right)}{\eta_{K}} r *-\frac{T_{1 K}^{*}}{\eta_{K}}\left[\rho_{12} \rho_{K 1}{ }^{\rho}{ }_{L 1}{ }^{1}{ }_{L K}+\rho_{21} \rho_{12} \rho_{K 1} \theta_{L 2} \sigma_{K 2}^{1}\left(1-\gamma \rho_{12} \rho_{K 1}\right)\right. \\
& \left.+\psi_{12}{ }_{1}{ }_{K 1}\left(\rho_{L 2} \theta_{K 1} \sigma_{L 1}^{2}-\rho_{K 2} \theta_{L 1} \sigma_{K 1}^{2}\right)+\gamma_{12}^{2}{ }_{12} \rho_{L 1} \rho_{K 1} \rho_{21} \theta_{K 2} \sigma_{L 2}^{1}\right]
\end{aligned}
$$




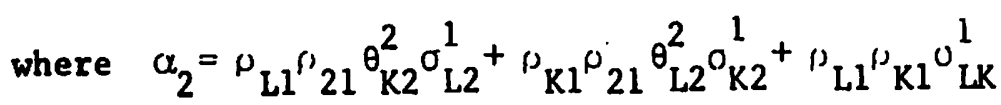

$$
\begin{aligned}
& \beta_{2}=\rho_{L 2}{ }^{\prime)} 12 \theta_{K 1}^{2} \sigma_{L 1}^{2}+\rho_{K 2} \rho_{12} \theta_{L 1}^{2} \sigma_{K 1}^{2}+\rho_{L 2}{ }^{()}{ }_{K 2} \sigma_{L K}^{2} \\
& \Omega_{L}=\rho_{L 1}+\rho_{L 2} \cdot \rho_{21}, \Omega_{K}=\rho_{K 1}+\rho_{K 2} \cdot \rho_{21} \\
& \eta_{L}=\rho_{L 2}+\rho_{L 1} \cdot \rho_{12}, \eta_{K}=\rho_{K 2}+\rho_{K 1} \cdot \rho_{12}
\end{aligned}
$$

These expressions, obviously, are very different from the corresponding $R_{i j}$ 's derived in the model with only pure intermediate goods.

\section{The Solutions for $r *$}

The two models are solved identically, by equating changes in supply and quantity demanded of $x_{1}$ (or $x_{1}$ in this case). Therefore, skipping all intermediate steps, only the final equations are presented below:

Value-Added Tax in $x_{1}\left(t_{v 1}\right)$

$$
r *=\frac{A_{e} \gamma\left(1-\rho_{12}\right)\left(\rho_{K 1}+\rho_{L 1}\right)+N_{1}\left(W_{1}-S_{1}\right)+N_{2}\left(W_{2}-S_{2}\right)}{D_{2}} T_{V 1}^{*}
$$

where $w_{1}=\rho_{K 1} \rho_{L 1} \sigma_{L K}^{1}+\rho_{21} \rho_{L 1} \theta_{K 2} \sigma_{L 2}^{1}\left(1-\gamma_{L 1} \rho_{12}\right)+\gamma_{K 1} \rho_{21} \rho_{12} \rho_{L 1} \theta_{L 2} \sigma_{K 2}^{1}$

$$
\begin{aligned}
& \left.+\gamma_{12} \rho_{21} \rho_{L 1}\left(\rho_{K 2} \theta_{L 1} \sigma_{K 1}^{2}-\mu_{L 2}{ }{ }_{K 1} \sigma_{L 1}^{2}\right)\right] \\
& s_{1}=\rho_{L 1} \rho_{K 1} \sigma_{L K}^{1}+\rho_{21} 1_{K 1} \theta_{L 2} O_{K 2}^{1}\left(1-\gamma /{ }_{12}{ }^{\prime} K_{K 1}\right)
\end{aligned}
$$

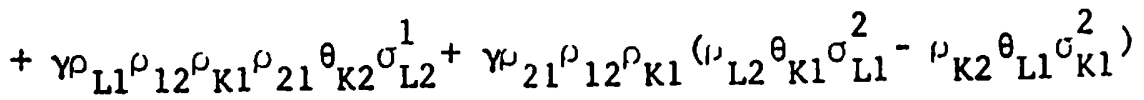

$$
\begin{aligned}
& w_{2}=\rho_{12} \rho_{K 1} \rho_{L 1} \sigma_{L K}^{1}+\rho_{12} \rho_{21} \rho_{L 1} \theta_{K 2} \sigma_{L 2}^{1}\left(1-\gamma \rho_{12} \rho_{L 1}\right)+\gamma_{L 1} \rho_{12}\left(\rho_{K 2} \theta_{L 1} \sigma_{K 1}^{2}-\rho_{L 2} \theta_{K 1} \sigma_{L 1}^{2}\right) \\
& +\gamma^{2}{ }_{12} \rho_{\mathrm{K} 1} \rho_{21}{ }^{\rho}{ }_{\mathrm{L} 1} \theta_{\mathrm{L} 2} \sigma_{\mathrm{K} 2}^{1} \\
& S_{2}=\rho_{12} \rho_{L 1} \rho_{K 1} \sigma_{L K}^{1}+\rho_{21} \rho_{12} \rho_{K 1} \theta_{L 2} \sigma_{K 2}^{1}\left(1-\gamma \rho_{K 1} \rho_{12}\right)+\gamma \rho_{K 1} \rho_{12}\left(\rho_{L 2} \theta_{K 1} \sigma_{L 1}^{2}-\rho_{K 2}{ }{ }_{L 1} \sigma_{K 1}^{2}\right) \\
& +\gamma_{12}^{2} \rho_{L 1} \rho_{K 1} \rho_{21} \theta_{K 2}{ }^{1}{ }_{L 2}^{1}
\end{aligned}
$$




$$
\begin{aligned}
& N_{1}=\left(\frac{1}{S_{L}} \frac{L_{1}}{L_{2}}+\frac{1}{\Omega_{K}} \frac{K_{1}}{K_{2}}\right), N_{2}=\left(\eta_{L}+\eta_{K}\right) / \gamma_{L} \pi_{K} \\
& D_{2}=A \in\left(\theta_{K 2}-\theta_{K 1}\right)+\left(\beta_{2}+\rho_{12} \alpha_{2}\right)\left(\frac{1}{\eta_{L}}+\frac{1}{\eta_{K}}\right)+\left(\alpha_{2}+\rho_{21} \beta_{2}\right)\left(\frac{1}{\Omega_{L}} \frac{L_{1}}{L_{2}}+\frac{1}{\Omega_{K}} \frac{K_{1}}{K_{2}}\right)
\end{aligned}
$$

and

$$
A=\left(K_{1} / K_{2}-L_{1} / L_{2}\right)
$$

A Tax on Capital in $\mathrm{x}_{1}$

$$
\mathrm{r}^{*}=\left[\mathrm{A} \in Y \rho_{\mathrm{K} 1}\left(1-\rho_{12}\right)-\mathrm{S}_{1} \mathrm{~N}_{1}-\mathrm{S}_{2} \mathrm{~N}_{2}\right] \mathrm{T}_{\mathrm{K} 1}^{*} / \mathrm{D}_{2}
$$

An excise tax on $x_{1}\left(t_{1}\right)$

$$
\begin{aligned}
r^{*}=[A \in & \left(1-\rho_{12}\right)+\rho_{12} \rho_{21}\left(N_{1}+\rho_{12} N_{2}\right)\left(\rho_{K 1} \theta_{L 2} \sigma_{K 2}^{1}-\rho_{L 1} \theta_{K 2} \sigma_{L 2}^{1}\right)+\rho_{12}\left(\rho_{21} N_{1}+N_{2}\right) \\
& \left.\left(\rho_{K 2} \theta_{L 1} \sigma_{K 1}^{2}-\rho_{L 2} \theta_{K 1} \sigma_{L 1}^{2}\right)\right] \gamma T_{1}^{*} / D_{2}
\end{aligned}
$$

Value-Added $\operatorname{Tax}$ in $\mathrm{X}_{2}$

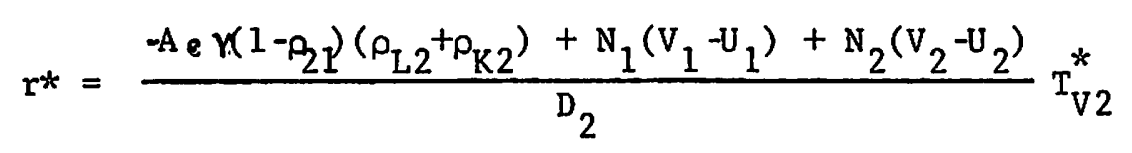

where $v_{1}=\gamma_{L 2} \rho_{21}\left(\rho_{K 1} \theta_{L 2} \sigma_{K 2}^{1}-\rho_{L 1} \theta_{K 2} \sigma_{L 2}^{l}\right)+\rho_{21} \rho_{K 2} \rho_{L 2} \sigma_{L K}^{2}$

$$
\begin{aligned}
& +p_{21}^{2} \rho_{K 2} \rho_{12} \rho_{L 2} \theta_{L 1} \sigma_{K 1}^{2}+\rho_{12} \rho_{21} \rho_{L 2} \theta_{K 1} \sigma_{L 1}^{2}\left(1-\gamma \rho_{21} \rho_{L 2}\right) \\
& \mathrm{U}_{1}=\gamma_{21} \rho_{\mathrm{K} 2}\left(\rho_{\mathrm{L} 1} \theta_{\mathrm{K} 2} \mathrm{o}_{\mathrm{L} 2}^{1}-\rho_{\mathrm{K} 1} \theta_{\mathrm{L} 2} \mathrm{i}_{\mathrm{K} 2}^{1}\right)+\mu_{21}{ }_{\mathrm{L} 2}{ }^{\rho}{ }_{\mathrm{K} 2} \mathrm{u}_{\mathrm{LK}}^{2} \\
& +\gamma{ }_{12}{ }^{\rho}{ }_{21} \rho_{K 2} \rho_{L 2} \theta_{K 1} \sigma_{L 1}^{2}+\rho_{21} \rho_{12} \rho_{K 2} \theta_{L 1} \sigma_{K 1}^{2}\left(1-\gamma \rho_{21} \rho_{K 2}\right)
\end{aligned}
$$




$$
\begin{aligned}
& v_{2}=\gamma \rho_{L 2} \rho_{21} \rho_{L 2}\left(\rho_{K 1} \theta_{L 2} \sigma_{K 2}^{1}-\rho_{L 1} \theta_{K 2}{ }^{1}{ }_{L 2}^{1}\right)+\rho_{K 2} \rho_{L 2} v_{L K}^{2} \\
& +\gamma \rho_{K 2}{ }^{\rho}{ }_{12} \rho_{21} \rho_{L 2}{ }^{\theta}{ }_{L 1} \sigma_{K 1}^{2}+\rho_{12} \rho_{L 2} \theta_{K 1} \sigma_{L 1}^{2}\left(1-\gamma \rho_{21} \rho_{L 2}\right) \\
& \mathrm{U}_{2}=\gamma \rho_{12} \rho_{21} \rho_{K 2}\left(\rho_{L 1} \theta_{K 2} \sigma_{L 2}^{1}-\rho_{K 1} \theta_{L 2} \sigma_{K 2}^{1}\right)+\rho_{L 2} \rho_{K 2} \sigma_{L K}^{2} \\
& +\gamma \rho_{12} \rho_{21} \rho_{K 2} \rho_{L 2}{ }^{{ }_{K 1}} \sigma_{L 1}^{2}+\rho_{12} \rho_{K 2} \theta_{L 1} \sigma_{K 1}^{2}\left(1-\gamma \rho_{21} \rho_{K 2}\right) .
\end{aligned}
$$

A Tax on Capital in $\mathrm{x}_{2}$

$$
r^{*}=-\left[A \in \gamma \rho_{K 2}\left(1-\rho_{21}\right)+U_{1} N_{1}+U_{2} N_{2}\right] T_{K 2}^{*} / D_{2}
$$

An Excise Tax on $\mathrm{X}_{2}$

$$
\begin{aligned}
r^{*}= & {\left[-A_{\epsilon}\left(1-\rho_{21}\right)+\rho_{21}\left(N_{1}+\rho_{12} N_{2}\left(\rho_{K 1} \theta_{L 2} \sigma_{K 2}^{1}-\rho_{L 1} \theta_{K 2} \sigma_{L 2}^{1}\right)+\rho_{12} \rho_{21}\left(\rho_{21} N_{1}+N_{2}\right)\right.\right.} \\
& \left.\left(\rho_{K 2} \theta_{L 1} \sigma_{K 1}^{2}-\rho_{L 2} \theta_{K 1} \sigma_{L 1}^{2}\right)\right] \gamma T_{2}^{*} / D_{2}
\end{aligned}
$$

These expressions are visibly more complex than those in the pure intermediate good case. This is really a reflection of the interdependence in production. In spite of their ponderous look, the W's, S's, U's and V's are simply weighted sums of elasticities of substitution, with factor shares serving as weights. All these terms will be zero if production coefficients are assumed to be fixed. There are, in effect, two intermediate goods which generate many links between the two industries. Consider, for instance, an excise tax on $x_{2}$. In the earlier model, the sign of $r^{*}$ is not affected by any elasticity of substitution in (13). In fact, $r^{*}$ is zero so long as demand is inelastic or the two final-good industries have the same gross capital-labor ratio. In this model, an excise tax on $x_{2}$ affects the 
input mix in $x_{1}$, and that, in turn, will influence the ratios in which $x_{1}$, the intermediate input, will be joined with labor and capital in $x_{2}$. Ordinarily, therefore, the wage-rental ratio will not stay put when an excise tax is levied.

\section{Comparison of VAT with CIT}

The assumptions used most commonly in comparing VAT with CIT in inputoutput models are that demand is inelastic and production coefficients are fixed. In the present case, whenever $\epsilon, \sigma_{\mathrm{KL}}^{1}, \sigma_{\mathrm{K} 2}^{1} \cdot \sigma_{\mathrm{L} 2}^{1}, \sigma_{\mathrm{K} 1}^{2}$, and $\sigma_{\mathrm{L} 1}^{2}$ are zero, VAT will not alter the factor-price ratio even if the $\operatorname{tax}$ is levied only in $\mathrm{x}_{1}$. However, in this situation, CIT also will not affect $w / r$, for $r^{*}$ will be zero in (32), and as equation (33) shows, an excise tax too will leave relative factor rewards unchanged. These curious results are easy to explain. A partial tax, whether levied on output or a factor of production in one industry creates a distortion in the system. Firms, in trying to minimize unit costs, will tend to substitute untaxed inputs for the taxed ones, and similar substitutions between final goods will happen on the demand side. The resulting interactions between demand and supply will lead to a new set of prices. The restrictions mentioned above effectively eliminate these substitution possibilities both in demand and the production process, so the wage-rental ratio remains unaltered. In such a restrictive setting, therefore, one cannot adequately compare VAT with other taxes. At the other extreme, if no restrictions are imposed on elasticities of demand or substitution, of the taxes being considered here, only VAT, levied at a uniform rate in every industry, will not affect factor prices. Equations (31) and (34) will always sum to zero while (32) and (35) (a tax on capital), and (33) and (36) (excise tax) will not. As in the earlier model, VAT turns out to be the only indirect tax : inder which, in the most general case, the wage-rental ratio remains constant. When only some of the restrictions mentioned above are imposed (e.g. A or $\varepsilon$ is zero), effects of VAT and other taxes will 
depend on empirical considerations, particularly on the magnitudes of various elasticities. Unlike the previous model, there are no taxes here that will leave the wage-rental ratio unchanged if demand is inelastic or factor ratios are the same in the two industries. and $\sigma^{\prime} s$ involving intermediate goods are zero in only one industry.

\section{Incidence of a Partial VAT}

Once again the incidence of a VAT levied in only one of the two industries can be examined. Notice that here as well, for precisely the reasons given for $D_{1}, D_{2}$ will be positive (but $D_{1}$ will not necessarily equal $\mathrm{D}_{2}$ ), so the sign of $\mathrm{r*}$ will depend on the numerators of the various expressions. Instead of a detailed analysis of (31) and (34), we focus on the differences between this and the earlier model.

of the propositions derived from (8) and (11) in the earlier model, only the second and fourth will hold as stated. Here also $\sigma_{\mathrm{KL}}^{1}$ and $\sigma_{\mathrm{KL}}^{2}$ appear only in the denominator of the various expressions for $r^{*}$. Therefore, they will affect the magnitude but not the sign of $r^{*}$ (Result 2). Regarding Result 4, it was stipulated there that all factor proportions were fixed, which implies that all $\sigma^{\prime} s$ are zero, so $W_{1}, s_{1}, W_{2}, S_{2}$, and $V^{\prime} s$ and $U^{\prime} s$ will be zero. Consequently, In (31) $r^{*}=\gamma\left(1-\rho_{12}\right)\left(\rho_{\mathrm{K} 1}+\rho_{\mathrm{L} 1}\right) /\left(\theta_{\mathrm{K} 2}-\theta_{\mathrm{K} 1}\right)$, and in $(34), r^{*}=\gamma\left(1-\rho_{21}\right)\left(\rho_{\mathrm{L} 2}+\rho_{\mathrm{K} 2}\right) /$ $\left(\theta_{\mathrm{K} 2}-\theta_{\mathrm{L} 2}\right)$. In either case $\epsilon$ does not appear. Therefore, the wage-rental ratio will not be affected by elasticity of demand.

Proposition 3 in the earlier model required that the two primary factors be used in fixed ratios with the intermediate good in the taxed industry. Now, if $\sigma_{\mathrm{L} 2}^{1}$ and $\sigma_{\mathrm{K} 2}^{1}$ are zero in (31), or $\sigma_{\mathrm{K} 1}^{2}$ and $\sigma_{\mathrm{L} 1}^{2}$ are zero in (34), the sign of $\mathrm{r}^{*}$ does not depend only on $A$, the gross factor intensity. Some elasticities of substitution still play a role. However, if the intermediate good cannot be substituted for capital and labor in either industry, i.e., $\dot{\sigma}_{\mathrm{L} 2}^{1}, \sigma_{\mathrm{K} 2}^{1}, \sigma_{\mathrm{K} 1}^{2}$, and $\sigma_{\mathrm{L} 1}^{2}$ are zero simultaneously, the sign of $\mathrm{r}^{*}$ will be deternined solely by $\mathrm{A}$. 
The first result derived in the earlier model will not be valid here. Because of interdependence in production, nothing can be concluded about $\mathrm{r}^{*}$ if only $\sigma_{\mathrm{L} 2}^{1}$ or $\sigma_{\mathrm{L} 1}^{2}$ are zero as was required in the earlier model. Restrictions on other $\sigma^{\prime} s$ will also be needed.

IV. Taxes and Relative Commodity Prices

One aspect of tax-neutrality is how various taxes affect commodity prices. VAT, if levied on every industry at a uniform rate, will be neutral in this regard, but other taxes, especially when they cause the wage-rental ratio to alter, will bring about a change in relative output prices. Such price effects are the subject of this section. They can be very important in devising tax programmes, particularly while choosing among different taxes which yield the same revenue. The most popular comparison has been between VAT and CIT which shall be taken up here as well. 11

The Pure Intermediate Good Model

In all the price equations set out earlier in the paper, there are two types of terms, one pertaining to factor prices $\left(r^{*}\right)$, and the other dealing with taxes directly. For example, in the case of VAT, we have

$$
\begin{aligned}
& \theta_{\mathrm{K} 1} \mathrm{r}^{*}+\left(\rho_{\mathrm{L} 1}+\rho_{\mathrm{K} 1}\right) \mathrm{T}_{\mathrm{V} 1}^{*}=\mathrm{p}_{1}^{*} \\
& \theta_{\mathrm{K} 2} \mathrm{r}^{*}+\left(\rho_{\mathrm{L} 2}+\rho_{\mathrm{K} 2}\right) \mathrm{T}_{\mathrm{V} 2}^{*}=\mathrm{p}_{2}^{*}
\end{aligned}
$$

As long as $\mathrm{T}_{\mathrm{V} 1}^{*}=\mathrm{T}_{\mathrm{V} 2}^{*}$, the share of value-added is the same in the two industries, and either $\mathrm{r}^{*}$ is zero or $\theta_{\mathrm{K} 1}=\theta_{\mathrm{K} 2}$, relative output price will not change $\left(p_{1}^{*}-p_{2}^{*}=0\right)$. If VAT is extended to the intermediate good as we1l, the only requirement for obtaining this result $\left(p_{1}^{*}-p_{2}^{*}=0\right)$ is that a uniform tax rate be applied because in this case, $\mathrm{r}^{*}$ will be zero as already proved, and both $p_{1}$ and $p_{2}$ will rise by the full amount of the tax. ${ }^{12}$ However, if the tax does not cover every industry, or is levied at different rates, there is no reason to believe that output-price ratio will be unaffected. 
The CIT Case

Under a tax on capital in $x_{1},(7)$ and the corresponding equation for $\mathrm{p}_{2}$ lead to $(38)$ :

$$
\left(\theta_{\mathrm{K} 1}-\theta_{\mathrm{K} 2}\right) \mathrm{r}^{*}+\rho_{\mathrm{K} 1} \mathrm{~T}_{\mathrm{K} 1}^{*}=\mathrm{p}_{1}^{*}-\mathrm{p}_{2}^{*}
$$

Even if $\mathrm{r}^{*}$ is zero, the two output prices will not change equally. Some situations nevertheless can arise in which the $r^{*}$ term exactly offsets the tax term. For example, if the taxed industry is capital intensive, so that $\theta_{\mathrm{K} 1}>\theta_{\mathrm{K} 2}$, r* will be negative in $(9)$, so $\mathrm{p}_{1}^{*}$ could well be equal to $\mathrm{p}_{2}^{*}$. However, it is highly unlikely in the U.S. case because the corporate sector is relatively labor-intensive, and there is considerable empirical evidence that $r^{*}$ has been negative. The two effects thus reinforce each other. 10 VAT vs. CIT

For a comparison between VAT and CIT, both levied in $\mathrm{X}_{1}$, the two taxes must yield the same revenue, which implies that $\mathrm{T}_{\mathrm{K} 1}^{*}=\mathrm{T}_{\mathrm{V} 1}^{*}\left(\rho_{\mathrm{K} 1}+\rho_{\mathrm{L} 1}\right) / \rho_{\mathrm{K} 1}$. The only relevant issue then is what happens to $r^{*}$, because using the tax rates and values of $\mathrm{r}^{*}$, effects on output prices can be readily determined from the price equations. Applying the equal yield condition, we obtain from (9)

$$
r * \frac{A \in\left(\rho_{L 1}+\rho_{K 1}\right)-B\left(\rho_{K 1} \rho_{M 1} \rho_{L M} \sigma_{K M}^{1}+\rho_{L 1} \rho_{K 1} \sigma_{L K}^{1}\right)\left(\rho_{L 1}+\rho_{K 1}\right) / \rho_{K 1} \theta_{L 1} \theta_{K 1}}{D_{1}} T_{V 1}^{*}
$$

The denominator and the first term in the numerator in (39) are the same as in (8). The term involving $\sigma_{\mathrm{KM}}^{1}$ is bigger than in (8) because it is being multiplied by $\left(\rho_{\mathrm{L} 1}+\rho_{\mathrm{K} 1}\right) / \rho_{\mathrm{K} 1}$. One more term is left in each expression: it involves $\sigma_{\mathrm{KL}}^{1}$ and makes a negative contribution in (39), but it includes $\sigma_{\mathrm{LM}}^{1}$ in (8) and is positive. All in all, $r^{*}$ will be more negative in (39) than in ( 8 ): 
other things being equal, VAT will lead to a smaller decline in the relative return to capital. This result can be easily explained. Under CIT, labor is substituted for capital in the corporate sector while there is no incentive to do so in case of VAT, consequently there is a smaller excess supply of capital and a lesser decline in its relative price under VAT. The wagerental ratio, however, will move identically in the two cases so long as all production coefficients are fixed in the taxed industry and the two taxes are constrained to yield the same revenue. In this event $r^{*}=\left(\rho_{\mathrm{L} 1}+\rho_{\mathrm{K} 1}\right) \mathrm{T}_{\mathrm{V} 1}^{*} /$ $\left(\theta_{\mathrm{K} 2}-\theta_{\mathrm{K} 1}\right)$ under VAT and $\rho_{\mathrm{K} 1} \mathrm{~T}_{\mathrm{K} 1}^{*} /\left(\theta_{\mathrm{K} 2}-\theta_{\mathrm{K} 1}\right)$ under CIT. The two will be identical when $\mathrm{T}_{\mathrm{K} 1}^{*}=\mathrm{T}_{\mathrm{V} 1}^{*}\left(\rho_{\mathrm{K} 1}+\rho_{\mathrm{L} 1}\right) / \rho_{\mathrm{K} 1}$.

Turning to output prices, we obtain from (6) and (37) (setting $\mathrm{T}_{\mathrm{V} 2}^{*}=0$ ):

$$
\left(\theta_{\mathrm{K} 1}-\theta_{\mathrm{K} 2}\right) \mathrm{r}^{*}+\left(\rho_{\mathrm{L} 1}+\rho_{\mathrm{K} 1}\right) \mathrm{T}_{\mathrm{V} 1}^{*}=\mathrm{p}_{1}^{*}-\mathrm{p}_{2}^{*}
$$

From (38) and (40) it is clear that if $\theta_{\mathrm{K} 1}<\theta_{\mathrm{K} 2}$, as is probably true in the United States, the relative output price in the taxed industry will rise less under VAT than in case of CIT, while the opposite result will hold if $\theta_{\mathrm{K} 1}>\theta_{\mathrm{K} 2}$. When production coefficients are fixed, the two taxes will of course affect relative output prices identically.

Here a comparison between CIT and a uniform VAT throughout the economy is also worth making. The latter will not alter the wage-rental ratio, nor will there be any effect on relative output prices. CIT will lead to different results on both counts. In fact, even when relative factor rewards stay unchanged (e.g., when $\sigma_{\mathrm{KM}}^{1}, \sigma_{\mathrm{LK}}^{1}$, and $\epsilon$ are zero), the relative price of the taxed commodity will rise: $\left(p_{1}^{*}-p_{2}^{*}\right)$ will be positive in (38) even if $r^{*}$ is zero.

\section{The Inter-Industry Flows Model}

The main difference between this and the earlier model is the interdependence in production which affects output-price equations, the solutions for $r *$ and many other aspects of the analysis. As equations (29) 
and (30) show, VAT in $X_{1}$ will affect both output prices irrespective of what happens to the wage-rental ratio. The same is true of CIT and every other tax in the system. Since there is no third good here, VAT in $x_{1}$ and $x_{2}$ at equal rate $\left(T^{*}\right)$ is like the comprehensive VAT in the earlier model, and it does not affect relative factor or commodity prices in the most general case, i.e., without any restrictions on the various parameters of the model. From the price equations (24) and (25) after incorporating VAT, it can be verified that $\theta_{\mathrm{K} 1} \mathrm{r}^{*}+\mathrm{T}^{*}=\mathrm{P}_{1}^{*}$, and $\theta_{\mathrm{K} 2} \mathrm{r}^{*}+\mathrm{T}^{*}=\mathrm{p}_{2}^{*}$, hence $\left(\mathrm{P}_{1}^{*}-\mathrm{P}_{2}^{*}\right)$ will be zero because $\mathrm{r}^{*}$ in this situation will be zero.

A Tax on Capital in $\mathrm{X}_{1}$ (CIT)

In this case, the relevant price equations lead to the following:

$$
\left(\theta_{\mathrm{K} 1}-\theta_{\mathrm{K} 2}\right) \mathrm{r}^{*}+\gamma \rho_{\mathrm{K} 1}\left(1-\rho_{12}\right) \mathrm{T}_{\mathrm{K} 1}^{*}=\left(\mathrm{p}_{1}^{*}-\mathrm{p}_{2}^{*}\right)
$$

Once again, even when $r^{*}$ is zero, the two output prices will respond differently. However, $\rho_{\mathrm{K} 1} \mathrm{~T}_{\mathrm{K} 1}^{*}$ here is premultiplied by $\gamma\left(1-\rho_{12}\right)$, so effect of CIT will not be the same as in the pure intermediate good model (equation $(38)$ ). This is really an empirical matter because everything depends on the values of $\gamma, \rho_{\mathrm{K} 1}$, and $\theta^{\prime} s$. Some numerical results reported by Bhatia (1980) show that with U.S. data for 1952-55, a value of r* equal to 0.5 will be sufficient to ensure no change in the relative output price. Plausible values of various parameters nonetheless point in the opposite direction- $-\theta_{\mathrm{K} 1}$ is less than $\theta_{\mathrm{K} 2}$ and $\mathrm{r}^{*}$ is negative--so the factor-price effect reinforces the tax effect.

VAT vs. CIT

If CIT is replaced by an equal-yield VAT in $x_{1}, T_{K 1}^{*}=T_{V 1}^{*}\left(\rho_{K 1}+\rho_{L 1}\right) / \rho_{K 1}$, and (32) is replaced by (42): 


$$
r *=\frac{\operatorname{Ae\gamma }\left(\rho_{\mathrm{K} 1}+\rho_{\mathrm{LI}}\right)\left(1-\rho_{12}\right)-\left(\mathrm{S}_{1} \mathrm{~N}_{1}+\mathrm{S}_{2} \mathrm{~N}_{2}\right)\left(\rho_{\mathrm{K} 1}+\rho_{\mathrm{L} 1}\right) / \rho_{\mathrm{Kl}}}{\mathrm{D}_{2}} \mathrm{~T}_{\mathrm{V} 1}^{*}
$$

The denominator, $\mathrm{D}_{2}$, and the first term in the numerator are common to both (30) and (42), but the other terms are complicated and their sign depends on empirical values, mostly of $\sigma^{\prime} s$ and various factor shares. Therefore, unlike the earlier model, one cannot definitely say how the wage-rental ratio will fare under these two taxes in $\mathrm{X}_{1}$. A definite statement can nevertheless be made in one instance: If all input-output coefficients are fixed in both industries, $\mathrm{r}^{*}$ will be identical under CIT and VAT. It will have the same sign as in the pure intermediate good model although the exact value of $r^{*}$ will be different.

The above results about $r^{*}$ carry over to output prices. From (29) and (30) we get:

$$
\left(\theta_{\mathrm{K} 1}-\theta_{\mathrm{K} 2}\right) \mathrm{r}^{*}+\gamma\left(\rho_{\mathrm{L} 1}+\rho_{\mathrm{K} 1}\right)\left(1-\rho_{12}\right) \mathrm{T}_{\mathrm{V} 1}^{*}=\mathrm{p}_{1}^{*}-\mathrm{p}_{2}^{*}
$$

Nothing a priori can be said about equations (41) and (43) except that when production coefficients are fixed, CIT and VAT will have an identical effect on relative output prices. Of course, if VAT applies to both industries, $\mathrm{r}^{*}$ will be zero and both output prices will rise by the same amount.

\section{Conclusions and Summary}

This paper has dealt with VAT in a general-equilibrium model of taxincidence. In the existing literature, VAT has been examined mostly in a partial-equilibrium context, often without incorporating intermediate goods into the analysis, and using the highly restrictive assumptions of fixed input-output coefficients and inelastic demand. One of the main results here is that when such restrictions are imposed, not only VAT but also partial factor taxes such as CIT turn out to be neutral. However, when production 
coefficients are allowed to vary and demand is elastic, VAT alone leaves relative factor and commodity prices unchanged as long as the tax applies at equal rates to every industry. As this is often difficult to achieve in practice, a number of results about the incidence and economic effects of a partial VAT are also derived. The main conclusion is that if VAT does not cover all industries, its incidence does not differ markedly from that of other partial taxes.

So far as relative output prices are concerned, in the most general case, VAT is the only tax that will not affect them. In more restrictive settings, with VAT and CIT levied in the same industries, the two taxes will affect relative output prices differently except when production coefficients are assumed to be fixed. In that case, substituting an equal-yield VAT for CIT will not alter the ratio of output prices. 


\section{Footnotes}

* Department of Economics, University of Western Ontario, London, Canada. I am grateful to Russ Mellett for his valuable research assistance.

$1_{\text {Tait }}(1972)$ has an extensive bibliography. A short review of the 1iterature is provided by Iindholm (1970) but he does not deal in depth with analytical studies. For a critique of this review, see Bird and Krauss (1971) and also Iindholm's rejoinder (1971). Country studies were the subject of a recent conference on VAT experience in Europe at the Brookings Institution. These will appear in a forthcoming Brookings volume edited by Henry Aaron.

2 Tait also adopts this approach although without using an input-output framework.

${ }^{3}$ Here it should be pointed out that this model and the one in the next section are different from a hierarchical framework which has been widely employed in the VAT literature. A typical example is McLure (1981) who specifies manufacturing, wholesale, and retail stages of production. A comparable case in the present model could be derived by specifying that $M$ is used in producing $x_{1}$ which in turn becomes an intermediate input in producing $\mathrm{x}_{2}$

${ }^{4}$ Each final-good industry uses labor and capital directly as well as through $i t s$ use of the intermediate good. If $a_{i j}$ is the direct requirement of labor or capital for one unit of the $j^{\text {th }}$ output, the gross or total requirement is $R_{i j}=a_{i j}+a_{M j} a_{i M^{*}}$ For instance, $R_{L 1}=a_{L I}+a_{M L} \cdot a_{L M^{\circ}}$ Factor shares computed from the $R$ 's are denoted by $\theta$ 's. All equations pertaining to the intermediate good, in a way, have been merged with the equations for final goods. 
5 Expression (5), which is also the demand function used by Harberger (1962) is based on the assumptions that the government balances its budget by spending tax revenue exactly as private individuals would have, and that all individuals have identical preferences. Consequently, there is only one independent demand function which depends on relative commodity prices alone. It is also assumed that there are no taxes in the initial situation.

${ }^{6}$ A casual glance at equation (6) might suggest that it applies to the "addition" or "subtraction" methods of computing VAT but not to the "taxcredit" method under which a firm subtracts VAT paid on its taxable purchases from the tax on its sales to compute tax liability. This view is erroneous because $\rho_{I 1}+\rho_{K 1}=1-\rho_{M}$ where $\rho_{M}$ is the share of the intermediate good in $X_{1}$. If the intermediate good is also subject to VAT at rate $t_{V 1}$, the taxterm in (6) will denote the change in net tax liability under the tax-credit method. If one is interested in analyzing such issues as 'exemption vs. zero rating '--the former causes a break in the chain of credits while the latter does not--it is perhaps better to use a hierarchical model referred to in footnote 3 with more than the two stages of production allowed in this model. For a numerical example, see McLure (1981), p. 133 or Shoup (1969), p. 260.

${ }^{7}$ of course, there can be additional effects on the side of uses of income which are ruled out here by the assumption of identical preferences.

${ }^{8}$ In these expressions, $\sigma$ 's in $X_{1}$ and $x_{2}$ are partial elasticities of substitution as defined by Allen (1969). For this purpose, the intermediate good, $M$, is really being treated as a third factor of production in $x_{1}$ and $x_{2}$. 
These $\sigma^{\prime}$ s can be positive or negative. However, as Allen shows, for a linear homogeneous production function with three inputs, either all $\sigma_{i k}$ 's ( $\left.i \neq k\right)$ are positive--which makes $\alpha_{1}$ and $\beta_{1}$ positive--or at most only one of the $\sigma^{\prime} s$ can be negative. Fortunately, even in this case $\alpha_{1}$ and $\beta_{1}$ will be positive (for a proof, see Batra (1974), pp. 177-79). Therefore, to limit the length of the paper, it is assumed that all $\sigma^{\prime}$ s are positive, i.e., all inputs are gross substitutes. The analysis, however, can be easily extended to cover complementary inputs (negative $\sigma^{\prime} s$ ).

${ }^{9}$ In this case, if $a_{K 1} / a_{L 1}>a_{K 2} / a_{L 2}, R_{K 1} / R_{L 1}$ will also be greater than $R_{K 2} / R_{L 2}$, as can be seen by expanding $R^{\prime} s$ in terms of the underlying $a^{\prime} s$. Cf. Batra (1974), pp. 157-58.

${ }^{10}$ See Tait (1972), Chapters 3 and 4 for a discussion of exemptions of this type.

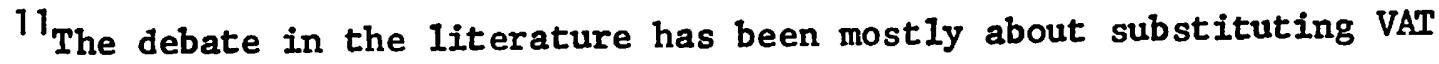
for CIT whereas much of the discussion here is in terms of imposing one tax or the other, starting from a neutral situation. The analysis, however, applies, mutatis mutandis, to both cases.

${ }^{12}$ Since only points of equilibrium are compared in this model, there is no room for assumptions of partial shifting of VAT which have been made by Dresch, Iin, and Stout (1977), for example, in analyzing first-round effects.

${ }^{13}$ Some empirical results along these lines are presented in Bhatia (1980). 


\section{$\underline{\text { References }}$}

Aaron, H., 1968, The differential price effects of a value-added tax, National Tax Journal 21, 162-175.

Allen, R. G. D., 1969, Mathematical analysis for economists (Macmillan, U.K.). Batra, R. N., 1974, Studies in the pure theory of international trade (Macmillan, U.K.).

Bhatia, K. B., 1981, Intermediate goods and the incidence of the corporation income tax, Journal of Public Economics 16, 93-112.

Bhatia, K. B., 1980, Factor taxes, commodity taxes, and relative prices, mimeographed.

Cnossen, S., 1981, Dutch experience with value-added taxation, mimeographed. Dresch, S. P., Iin, A., and Stout, D. K., 1977, Substituting a value-added tax for the corporate income tax (Ballinger, U.S.A.).

Friedlaender, A. F., 1967, Indirect taxes and relative prices, Quarterly Journal of Economics $81,125-39$.

Harberger, A. C., 1962, The incidence of the corporation income tax, Journal of Political Economy 70, 215-40.

Krauss, M. and Bird, R. M., 1971, The value-added tax: critique of a review, Journal of Economic Literature 9, 1167-73.

Lindholm, R. W., 1971, The value added tax: rejoinder to a critique, Journal of Economic Literature 9, 1173-79.

Mieszkowski, P. M., 1967, On the theory of tax incidence, Journal of Political Economy 75, 250-62. 
McLure, C. E., Jr., 1972, The tax on value added: pros and cons in McLure, C. E. Jr., and Ture, N. B., Value added tax: two views (American Enterprise Institute, Washington, D.C.).

McLure, C. E., Jr., 1981, VAT versus the payroll tax, F. Skidmore, ed., Social security financing (MIT Press, Cambridge), 129-164.

Oakland, W. H., 1967, The theory of the value-added tax: I, a comparison of tax bases, National Tax Journal 20, 119-36.

Oakland, W. H., 1967, The theory of the value-added tax: II, incidence effects, National Tax Journal 20, 270-81.

Shoup, C. S., 1969, Experience with value-added tax in Denmark, and prospects in Sweden, Finanzarchiv 28, 236-52.

Shoup, C. S., 1969, Public finance (Aldine, Chicago).

Tait, A. A., 1972, Value added tax (McGraw-Hill, London).

Vartholomeos, J., 1974, Price and trade effects of the substitution of a valueadded tax for the corporate income tax: the British case, Finanzarchiv $32,469-80$. 


\section{Appendix}

Some of the steps required for arriving at $a_{i j}^{*}$ and $R_{i j}^{*}$ in the interindustry model are given below to illustrate the general approach. For the other model, refer to the appendix in Bhatia (1981).

$$
a_{i j}=a_{i j}\left(w, r, p_{k}\right)(i=L, K, 1,2 ; j, k=1,2 ; j \neq k)
$$

By totally differentiating $(1)$ we get $\left(w^{*}=0\right)$ :

$$
\begin{aligned}
& a_{K 1}^{*}=-\rho_{I 1} \sigma_{L K}^{1} r^{*}+\rho_{21} \sigma_{K 2}^{1} p_{2}^{*} \\
& a_{21}^{*}=-\rho_{K 1} \sigma_{K 2}^{1} x^{*}+\rho_{21} \sigma_{22}^{1} p_{2}^{*}
\end{aligned}
$$

The partial elasticity of substitution between labor and capital in the first industry can be defined as :

$$
\rho_{I I} \sigma_{K L}^{1}=\frac{\partial a_{K 1}}{\partial w} \cdot \frac{w}{a_{K 1}} .
$$

Definitions of other $\sigma$ 's are analogous. We know (Allen. (1969), p. 505) that

$$
\rho_{\mathrm{Ll}} \sigma_{\mathrm{LL}}^{1}+\rho_{\mathrm{Kl}} \sigma_{\mathrm{LK}}^{1}+\rho_{\mathrm{KM}} \sigma_{\mathrm{LM}}^{1}=0
$$

Equations (2) and (3) can be simplified by using (4) and the price equations in the paper.

$$
\begin{aligned}
& \text { Recall that by definition } R_{K 1}=\left(a_{K 1}+a_{K 2} a_{21}\right) /\left(1-a_{12} a_{21}\right) \text {. Therefore, } \\
& R_{K 1}^{*}=\frac{d R_{K 1}}{R_{K 1}}=\frac{a_{K 1} a_{K 1}^{*}+a_{21} a_{K 2} a_{21}^{*}+a_{21}\left(a_{K 2} a_{K 2}^{*}+a_{12} R_{K 1} a_{12}^{*}\right.}{a_{K 1}+a_{K 2} a_{21}}
\end{aligned}
$$

Simple substitutions and rearranging of terms complete the derivation. 